\title{
ANALYSIS OF AN AUTOMATIC VALVE GEOMETRY FOR CONCRETE AND DRILLING MUD PUMPS TO AVOID CAVITATION: NON-NEWTONIAN CFD MODELLING
}

\author{
FRANCO CONCLI ${ }^{1} \&$ CARLO GORLA ${ }^{2}$ \\ ${ }^{1}$ Faculty of Science and Technology, Free University of Bolzano/Bozen, Italy \\ ${ }^{2}$ Department of Mechanical Engineering, Politecnico di Milano, Italy
}

\begin{abstract}
A mud pump is a reciprocating liner (piston/plunger) pump designed to circulate drilling fluid under high pressure down the drill string and back up the annulus. A mud pump is an important part of the equipment used for oil well drilling. The automatic valves of the fluid-end produce the pumping effect. The valves consist of a movable body and a reaction spring. The spring is designed in order to avoid leakage and prevent contact between the valve itself and the retaining cage. Its proper sizing depends on the operating conditions as well as the properties of the fluid. The valve seat geometry significantly contributes to ensure the tightness of the fluid-end. An aspect that should be carefully considered during the design of new geometries is the phenomenon of cavitation. Cavitation consists in the development of vapour cavities in the liquid phase. Inside the cavities the pressure is relatively low. When subjected to higher pressure, the voids implode and generate an intense shock wave that promotes the wear of the components (i.e. valve, valve seat, etc.). A deep understanding of the fluid behaviour is crucial for an effective design. Transient CFD simulations of the valve opening have been performed using a nonNewtonian fluid model able to describe the drilling muds. After a deep literature review, the HerschelBulkley model was selected as the most suitable for emulating the drilling mud. With the above mentioned approach, the reaction spring and valve seat were designed properly to avoid premature wear phenomena.
\end{abstract}

Keywords: CFD, concrete, drilling mud, Herschel-Bulkley, pump, valve, cavitation.

\section{INTRODUCTION}

The fluid flow inside a pumps involves complex phenomena such as turbulence, unsteadiness and cavitation. In the past, experimental testing was one of the most common ways for the prediction of the performances of pumps. However, this approach is very expensive and timeconsuming.

For a cost-effective design of a pump, it is crucial to predict the performances before manufacturing the prototype, but this is not trivial and implies a deep understanding of the flow behaviour. The recent developments in Computer Science and Computational Fluid Dynamic (CFD) have promoted a better understanding of the fluids' behaviour and have strengthen the design procedure.

The application of CFD to the design of pumps started about 30 years ago [1]. The first models were characterized by simplified Quasi-3D Euler conditions and potential flow solutions. Afterwards, Reynolds Averaged Navier-Stokes (RANS) equations were introduced. Eventually, the presence of more than one phase and mass exchange models between the phases have been developed and included in many simulation codes.

Different commercial and open-source CFD software are available nowadays. Among the traditional Finite Volume (FV) based software, the most widespread are: Ansys Fluent [2] and OpenFOAM ${ }^{\circledR}[3]$.

These include not only models for Newtonian fluids but also for non-Newtonian fluids. This capability enables also the study of particular fluids like muds and concretes. 
The last developments in fluid dynamics involve Lagrangian methods and Smoothed Particle Hydrodynamics (SPH) [4]. Dualsphysics [5] and nanoFluidX [6], just to mention some of them, are examples of such kind of simulation tools.

\section{PROBLEM DESCRIPTION}

Reciprocating liner pumps are typically used to make muds circulate under high pressure during drilling operations or to pump fresh concrete.

The typical configuration of this kind of pump uses a triple piston/plunger. Each pump consists of three main sub-assemblies, the mechanical power transmission, the power end and the fluid end (see Fig. 1).

The fluid end produces the pumping process and is composed by several components: valves, pistons and liners. These components are subjected to high-wear during operation, mainly due to cavitation effects. On the other side, the power end converts the rotation of the drive shaft into a reciprocating motion of the pistons.

The fluid end contains two automatic valves, one for the suction- and one for the pump delivery-port. Both valves are equipped with springs: when the piston is at the dead centres, the valves are closed. The motion of the piston (from the top dead centre to the bottom dead centre) produces a depressurization of the internal chamber. The pressure gradient between the internal and external surfaces of the inlet valve produces an hydraulic force, whose magnitude overcomes the reaction force of the (pre-loaded) spring, leading to the opening of the valve (the equilibrium position depends on the spring stiffness and the hydraulic force that is related to the motor speed and the fluid properties). The fluid is sucked in the pump chamber. The piston is in the bottom dead centre and inverts its motion starting to pressurise the chamber. The spring of the delivery valve is pre-loaded but is mounted outside the pressurized chamber (Fig. 2). The increasing pressure produces the opening of that valve and the pumping of the fluid.

During the pumping stage, the fluid is under high pressure, but during the suction stage, the pressure can locally sink down to the vaporization value (that is a property of the fluid), leading to a phase transition (from liquid to vapour - namely, cavitation). This phenomena should be avoided to prevent excessive wear of the components. Cavitation, in fact, consists in the development of vapour cavities in the liquid phase. When subjected to higher pressure, these voids implode and generate intense shock waves that promote the wear of the components.

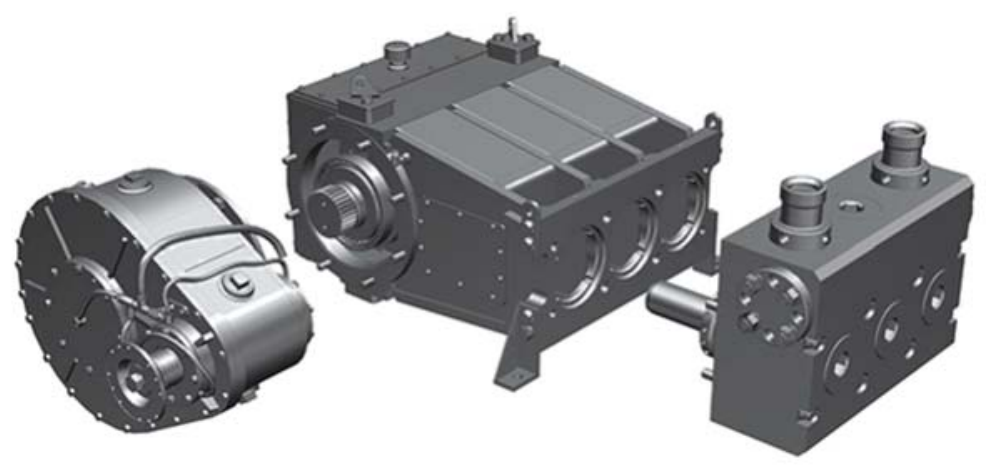

Figure 1: Typical layout of a motor pump: mechanical power transmission (left), power end (centre) and fluid end (right). www.jasonoandg.com/product/600s-triplexplunger-pump.htm. 


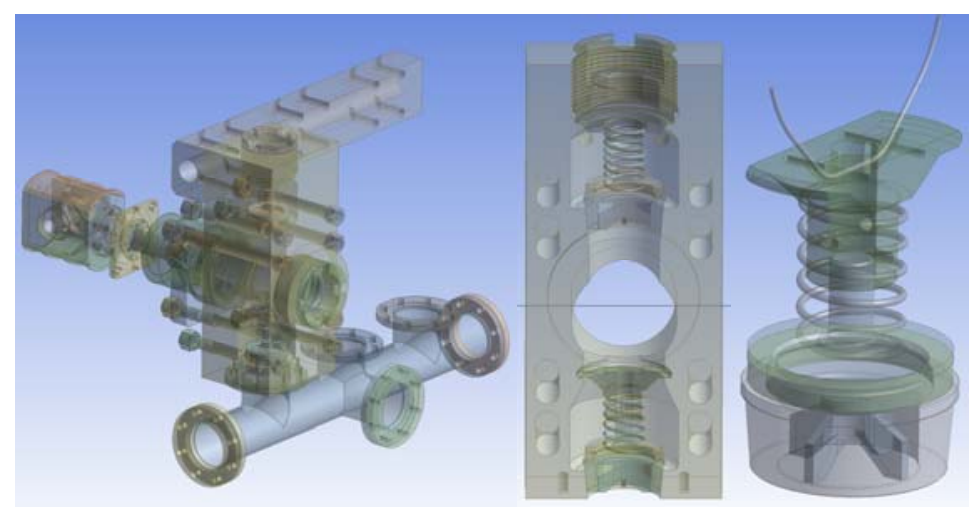

Figure 2: Typical layout of a fluid end of a triplex mud pump (left); fluid end (centre); suction valve (centre-right).

For this reason, dedicated CFD simulations have been performed in order to verify the absence of cavitation during pumps operation and to ensure an adequate life to the valves.

\section{NUMERICAL SETUP}

In the present research, the liner, the piston, part of the pressurized chamber and all the components (seals, spring, seat etc.) of an automatic suction valve were modelled in Ansys Fluent. A semi-transient approach was used. In order to avoid mesh deformation and the related computational efforts and problems [8]-[10], simulations were performed keeping fixed the position of the valve (a) while the piston velocity was a function of the simulation time (to reproduce its simple harmonic motion induced by the crankshaft).

Just half of the domain was modelled taking advantage of the symmetry, so to reduce the amount of computational cells and speed up the numerical solution phase. All the boundaries were set to "walls" except for the suction-section (inlet), the piston (outlet) and the symmetry plane. Table 1 reports the boundary conditions for $p, v$.

The adopted model solves two equations that mathematically represent the mass and momentum conservation equations and can be written as:

$$
\begin{gathered}
\frac{\partial \rho}{\partial t}=\operatorname{div}(\rho \boldsymbol{u})=0 \\
\frac{\partial(\rho \boldsymbol{u})}{\partial t}+\nabla \cdot(\rho \boldsymbol{u u})=-\nabla p+\nabla \cdot[\boldsymbol{\tau}]+\rho \boldsymbol{g}+\boldsymbol{F},
\end{gathered}
$$

where $\rho$ is the density, $\boldsymbol{u}$ is the velocity vector, $p$ is the pressure, $\boldsymbol{g}$ is the gravitational force and $\boldsymbol{F}$ a generic external force.

Table 1: Boundary conditions.

\begin{tabular}{|c|c|c|c|c|c|}
\hline Patch name & Symmetry & Suction & Piston & Valve & Housing \\
\hline Type & Symmetry & Patch & Patch & Wall & Wall \\
\hline $\mathrm{p}$ & $\nabla p=0$ & $p=$ const & $\nabla p=0$ & $\nabla p=0$ & $\nabla p=0$ \\
\hline $\mathrm{v}$ & $\nabla v=0$ & $\nabla v=0$ & $v=$ const & $v=0$ & $v=0$ \\
\hline
\end{tabular}


If the fluid is Newtonian, incompressible and the viscosity is constant, $\boldsymbol{\tau}$ (shear stress) can be written as $\boldsymbol{\tau}=\mu\left(\nabla \boldsymbol{u}+\nabla \boldsymbol{u}^{T}\right)$. The relation between the shear stress and the shear rate is linear, passing through the origin, the constant of proportionality being the coefficient of viscosity $\mu$.

A non-Newtonian fluid is a fluid that doesn't follow Newton's law of viscosity. Most commonly, the viscosity of non-Newtonian fluids is a function of the shear rate. The fluid can even exhibit time-dependent viscosity. Therefore, a constant coefficient of viscosity cannot be defined.

Fluids like concretes, muds and slurry [7] are non-Newtonian and have a behaviour that can be described via the Herschel-Bulkley model [11]-[13], combining the features of both the Bingham Plastic and Power Law models.

The Herschel-Bulkley is a generalized model of a non-Newtonian fluid, in which the strain experienced by the fluid is related to the stress in a complicated, non-linear way. The constitutive equation of the Herschel-Bulkley model is commonly written as:

$$
\boldsymbol{\tau}=\tau_{0}+\eta \boldsymbol{D},
$$

in which $\boldsymbol{D}$ is the rate-of-deformation tensor.

For low strain-rates $\dot{\gamma}<\dot{\gamma}_{c}=\tau_{0} / \mu_{0}$ the "rigid" material acts like a very viscous fluid with a viscosity $\mu_{0}$. As the strain rate increases and the yield stress threshold, $\tau_{0}$, is passed, the fluid behaviour is described by a power law.

For $\dot{\gamma}>\dot{\gamma}_{c}$

$$
\eta=\frac{\tau_{o}}{\dot{\gamma}}+K\left(\frac{\dot{\gamma}}{\dot{\gamma}_{c}}\right)^{n-1}
$$

For $\dot{\gamma} \leq \dot{\gamma}_{c}$

$$
\eta=\frac{\tau_{o}}{\dot{\gamma}}\left(2-\frac{\dot{\gamma}}{\dot{\gamma}_{c}}\right)+K\left((2-n)+(n-1) \frac{\dot{\gamma}}{\dot{\gamma}_{c}}\right),
$$

in which $\tau=\eta(\boldsymbol{D}) \boldsymbol{D}$ is the shear stress, $\dot{\gamma}$ is the shear rate, $\tau_{0}$ is the yield stress (that would allow cuttings to float under static conditions), $k$ the consistency index and $n$ the flow index. It is noted here that the concept of yield stress has been challenged [14] because a fluid may deform minutely at stress values lower than the yield stress. Nevertheless, yield stress may be considered to be an engineering reality and plays an important role. Estimated values of yield stress should be used only when experimentally-determined values are not available [15].

The fluid (fresh concrete) parameters have been taken from literature [16], [17] and are reported in Table 2. Nguyens reports the rheological characteristics for different waterconcrete mixtures. Abrahamsson does not specify the exact fluid but, as Fig. 3 shows, the behaviour is compatible with a fresh concrete which water-concrete $(\mathrm{W} / \mathrm{C})$ ratio is between 0.5 and 0.55 .

Table 2: Fluid parameters.

\begin{tabular}{|l|c|c|c|c|c|}
\hline Model & $\tau_{0}(\mathrm{~Pa})$ & $k(\mathrm{~Pa})$ & $n(-)$ & $\rho\left(\mathrm{kg} / \mathrm{m}^{3}\right)$ & $\dot{\gamma}(1 / \mathrm{s})$ \\
\hline Abrahamsson & 8 & 2.5 & 0.35 & 1,400 & 1 \\
\hline Nguyen W/C=0.5 & 8.1 & 3.87 & 0.408 & 1,816 & 1 \\
\hline Nguyen W/C $=0.55$ & 5.6 & 1.84 & 0.454 & 1,766 & 1 \\
\hline
\end{tabular}



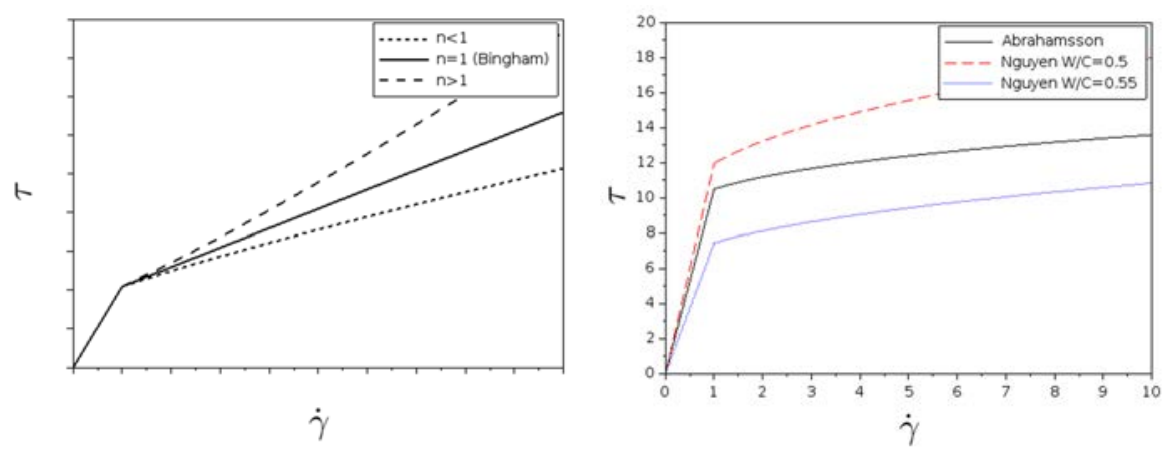

Figure 3: Variation of shear stress with shear rate according to the Herschel-Bulkley model (left); Herschel-Bulkley model according to Table 2.

Fig. 4 shows clearly the difference in terms of velocity profiles between a non-Newtonian (fresh concrete) and a Newtonian (water) fluid.

\section{RESULTS}

Different valve openings (a) have been simulated with variable piston positions (x) and velocities (Fig. 5).

The resultant force given by the integral of the pressures on the valve summed to the viscous contribution is reported, for the different conditions, in Figs 8 and 9.

The hydraulic force acting on the valve is a function of the valve opening (a) and the piston velocity. The maximum value at equilibrium (with the reaction of the spring) is in correspondence of a valve opening of about $10 \mathrm{~mm}$. The minimum pressure takes place on the sharp edge of the valve (Fig. 6). Its magnitude is of about -4E4 Pa. Considering that the vaporization pressure of water is about 2.3E3 $\mathrm{Pa}$, cavitation could take place. The presence of a pressure booster $(\Delta \mathrm{p}>1 \mathrm{E} 5 \mathrm{~Pa})$ can prevent such a phenomenon.

Fig. 7 shows the differences between Newtonian (water) and non-Newtonian (fresh concrete) behaviour. In case of water, the streamlines are uniform and bundled. With fresh concrete the streamlines appears quasi-randomly distributed.
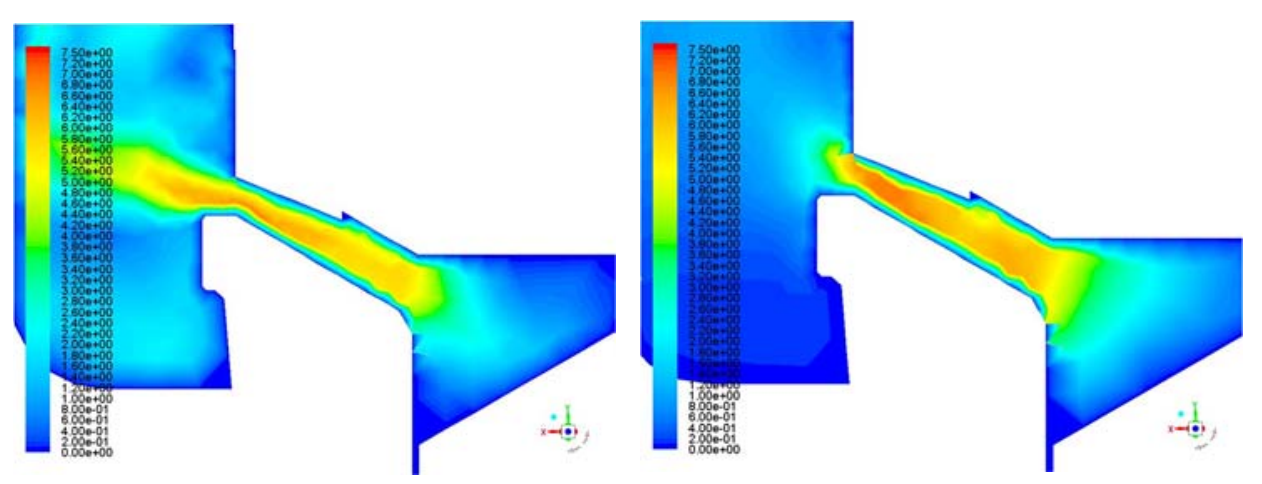

Figure 4: Velocity contours in the valve opening: non-Newtonian (left); Newtonian (right). 


\begin{tabular}{|c|c|c|c|}
\hline & $\mathrm{x}=175 \mathrm{~mm} ; \mathrm{v}=0.4 \mathrm{~m} / \mathrm{s}$ & $\mathrm{x}=90 \mathrm{~mm} ; \mathrm{v}=1.4 \mathrm{~m} / \mathrm{s}$ & $\mathrm{x}=29 \mathrm{~mm} ; \mathrm{v}=0.925 \mathrm{~m} / \mathrm{s}$ \\
\hline 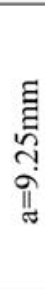 & 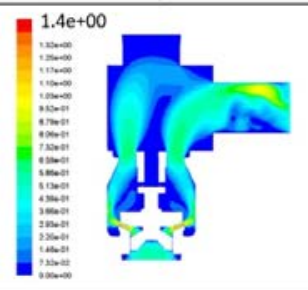 & 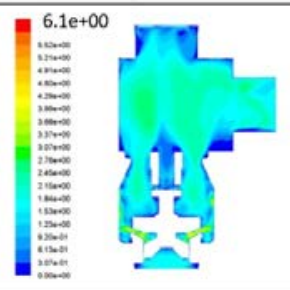 & 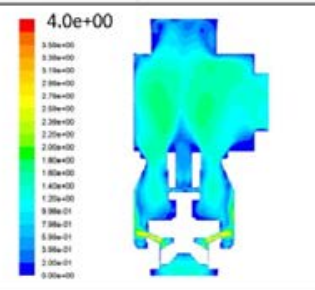 \\
\hline 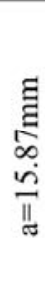 & 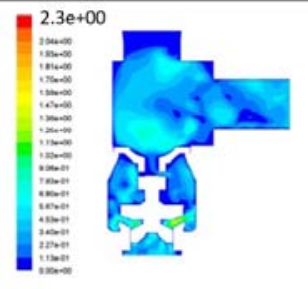 & 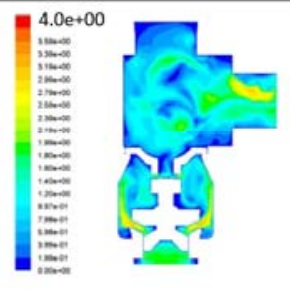 & $=\begin{array}{l}3.00+00 \\
=\infty \\
=\infty\end{array}$ \\
\hline 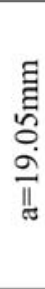 & 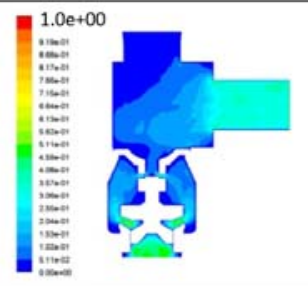 & 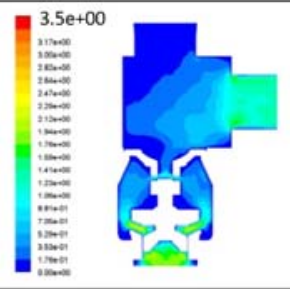 & $\begin{array}{ll}2.5 \mathrm{e}+00 \\
= \\
= \\
=\end{array}$ \\
\hline
\end{tabular}

Figure 5: Velocity contours on the symmetry plane: different valve opening (a) and piston position (x).

\begin{tabular}{|l|l|l|}
\hline $\begin{array}{l}\mathrm{a}=2 \mathrm{~mm} ; \\
\mathrm{v}=0.22 \mathrm{~m} / \mathrm{s}(\mathrm{F}=98 \mathrm{~N})\end{array}$ & $\begin{array}{l}\mathrm{a}=5 \mathrm{~mm} ; \\
\mathrm{v}=0.91 \mathrm{~m} / \mathrm{s}(\mathrm{F}=125 \mathrm{~N})\end{array}$ & $\begin{array}{l}\mathrm{a}=10 \mathrm{~mm} ; \\
\mathrm{v}=1.23 \mathrm{~m} / \mathrm{s}(\mathrm{F}=176 \mathrm{~N})\end{array}$ \\
\hline & & \\
\hline
\end{tabular}

Figure 6: Pressure contours on the valve at equilibrium positions (valve opening - piston velocity).

Being the flow index $n$ of the considered fluid below 1 (Table 2), shear thinning (decrease of viscosity under high shear strain) takes place. This reflects in a different velocity profile in the flow.

The wall shear stress results higher (on average) for the fresh concrete where the shear rates are lower (in the main chamber). However it results significantly higher for the water in the valve clearance, where the shear rate is maximum and shear thinning occurs for the fresh concrete (Fig. 3). 


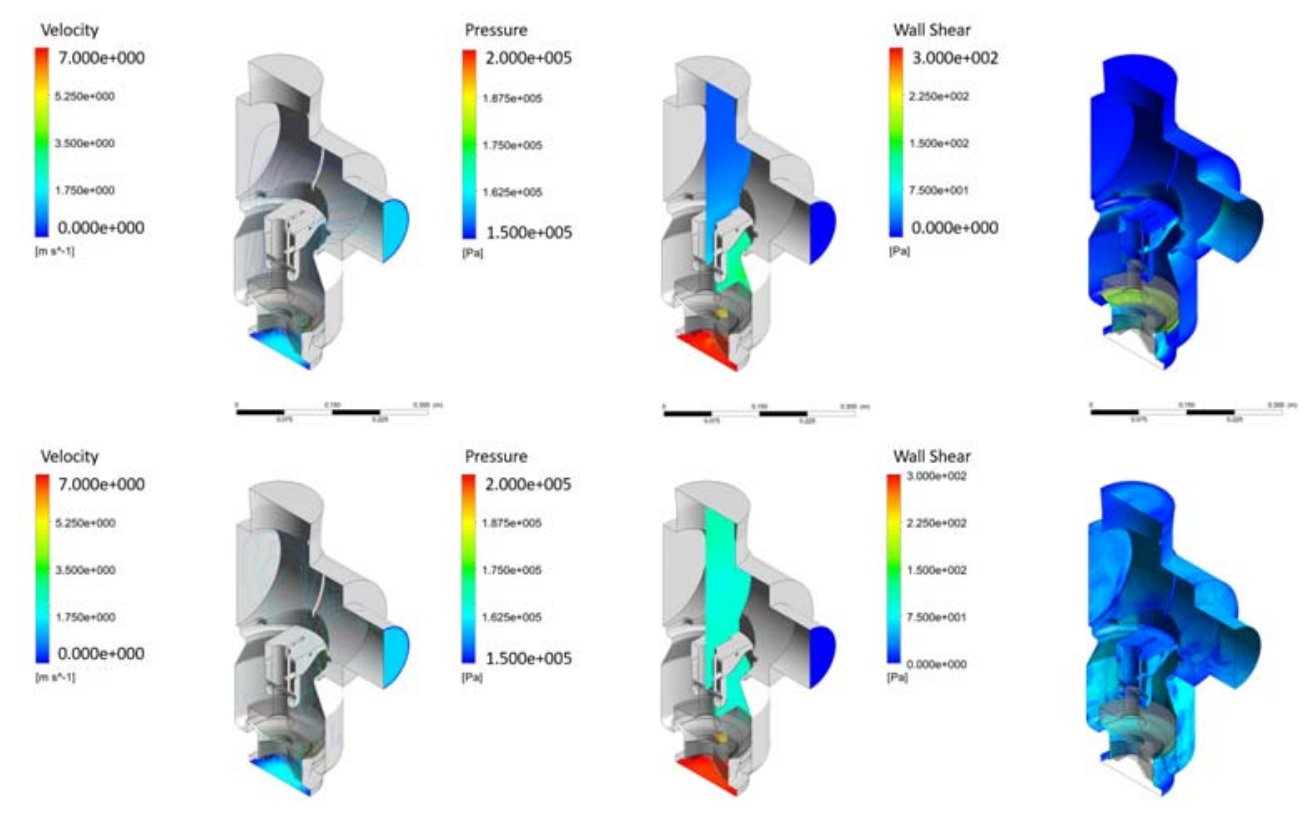

Figure 7: Velocity contours and streamlines (left), pressure contours (centre) and wall shear stresses (right) for Newtonian (top) and non-Newtonian (bottom) fluids.

Fig. 8 shows the relation between the valve opening (a) and the piston speed (v): the relation is not linear. For low piston velocities (i.e. when the piston is near the top or bottom dead centre), the valve clearance (function of the valve opening a) is close to zero. Due to the viscous properties of the fluid, high local velocities take place in the gap between valve and valve seat. On the other side, when the valve position reaches its maximum, the clearance is much higher and the main contribution to the hydraulic forces is given by inertial effects.

\section{PERFORMANCE ENHANCEMENTS}

All the simulations have been performed on an Intel Xeon E5620@2,40GHz x 2 (8 cores) 76.8 GFLOPS workstation with Ansys Fluent 17. In presence of small gaps [18], and specifically between the valve and the valve seat, the size of the mesh results significantly reduced and the computational time increases significantly. Some specific techniques can be applied when the viscous contribution can be neglected [19], [20], but this is not the case. Despite of the symmetry, more than 2 million cells are required in order to properly discretize the domain. This has led, on the abovementioned workstation, on a computational effort for each semi-transient simulation (with fixed valve position) of about $15 \mathrm{~h}$ per simulation.

\section{CONCLUSIONS}

The capability of modern CFD tools to describe the behaviour of non-Newtonian fluids could represent a valid support in the design and analysis of complex systems such as pumps.

The equilibrium position of the valve depends (at each time step) from the pressure and velocity fields that are, in turn, function of the piston velocity and the fluid properties. 

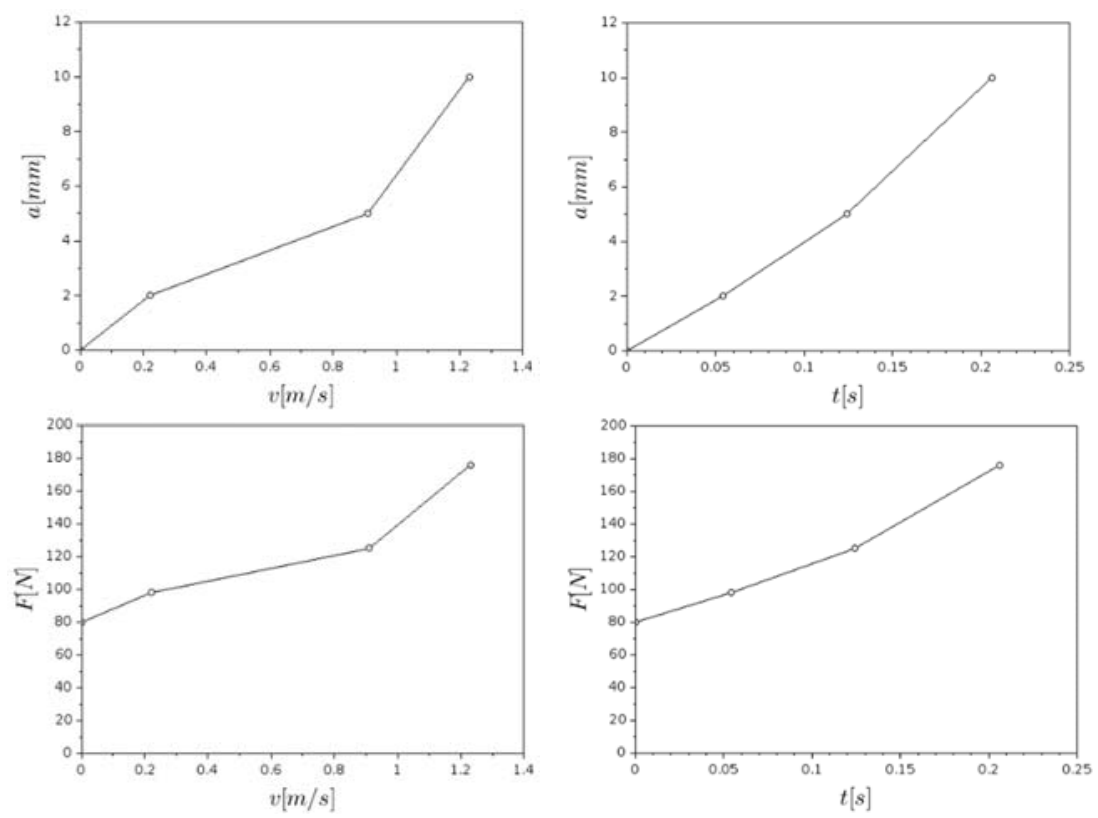

Figure 8: Valve opening (a) at equilibrium (top) and reaction force (F) of the spring (bottom) vs. piston speed (left) and time (right).
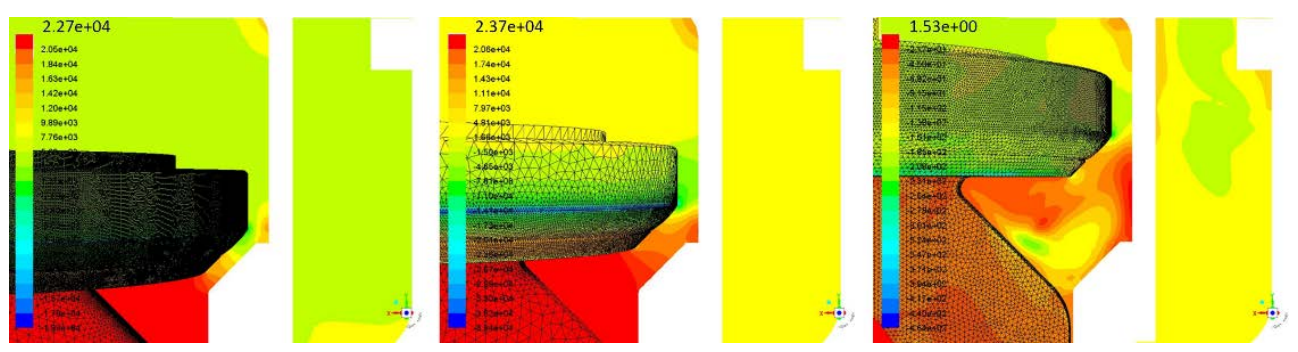

Figure 9: Pressure contours at different equilibrium positions (a).

With a semi-transient approach in which the valve opening was kept fixed while the piston velocity was a function of the time, it was possible to find the equilibrium position of the valve (at each time).

Cavitation is a phenomenon that should be eliminated in order to reduce the wear of automatic-valves. Knowing the minimum pressure during pumping operations allows to properly size the required booster.

\section{REFERENCES}

[1] Shah, S.R., Jain, S.V., Patel, R.N. \& Lakhera, V.J., CFD for centrifugal pumps: A review of the state-of-the-art. Procedia Engineering, 51, pp. 715-720, 2013.

[2] www.ansys.com/products/fluids.

[3] www.openfoam.com. 
[4] Concli, F. \& Gorla, C., Windage, churning and pocketing power losses of gears: different modelling approaches for different goals (Wirkungsgrad und Verluste von Zahnradgetrieben: Verschiedene Methoden für verschiedene Anwendungen). Forschung im Ingenieurwesen/Engineering Research, 80(3-4), pp. 85-99, 2016.

[5] www.dual.sphysics.org.

[6] www.fluidyna.com/content/nanofluidx.

[7] Bietresato, M., Friso, D. \& Sartori, L., An operative approach for designing and optimising a pipeline network for slurry collection from dairy farms across a wide geographical area. Biosystems Engineering, 115(3), pp. 354-368, 2013.

[8] Concli, F. \& Gorla, C., Numerical modelling of the churning power losses in planetary gearboxes: An innovative partitioning-based meshing methodology for the application of a computational effort reduction strategy to complex gearbox configurations. Lubrication Science, 29(7), pp. 455-474, 2017.

[9] Concli, F., Thermal and efficiency characterization of a low-backlash planetary gearbox: An integrated numerical-analytical prediction model and its experimental validation. Proceedings of the Institution of Mechanical Engineers, Part J: Journal of Engineering Tribology, 230(8), pp. 996-1005, 2016.

[10] Concli, F. et al., Load independent power losses of ordinary gears: Numerical and experimental analysis. 5th World Tribology Congress, WTC 2013, 2, pp. 1243-1246, 2013.

[11] Herschel, W.H. \& Bulkley, R., Konsistenzmessungen von Gummi-Benzollösungen. Kolloid-Zeitschrift, 39(4), pp. 291-300, 1926.

[12] Herzhaft, B., Rousseau, L., Neau, L., Moan, M. \& Bossard, F., Influence of temperature and clays/emulsion microstructure on oil-based mud low shear rate rheology. SPE J., 8(3), pp. 211-217, 2003.

[13] Kenny, P. \& Hemphill, T., Hole-cleaning capabilities of an ester-based drilling fluid system. SPE Drill. Complet., 11(1), pp. 3-9, 1996.

[14] Walters, K., An Introduction to Rheology, Volume 3, Elsevier Science, 1989.

[15] Rao, M.A., Rheology of Fluid, Semisolid, and Solid Foods, Food Engineering Series, Springer Science+Business Media: New York, 2014.

[16] Abrahamsson, J., Product losses of highly viscous products in pipe systems during displacement processes. MSc thesis, Division of Fluid Mechanics, Department of Energy Sciences Faculty of Engineering Lund University, Sweden.

[17] Nguyen, V.H., Rémond, S., Gallias, J.L., Bigas, J.P. \& Muller, P., Flow of HerschelBulkley fluids through the Marsh cone. Journal of Non-Newtonian Fluid Mechanics, 139(1-2), pp. 128-134, 2006.

[18] Concli, F. \& Gorla, C., Analysis of the oil squeezing power losses of a spur gear pair by mean of CFD simulations, ASME 2012 11th Biennial Conference on Engineering Systems Design and Analysis, ESDA 2012, 2, pp. 177-184, 2012.

[19] Concli, F. \& Gorla, C., Oil squeezing power losses in gears: A CFD analysis. WIT Transactions on Engineering Sciences, vol. 74, WIT Press: Southampton and Boston, pp. 37-48, 2012.

[20] Concli, F., Della Torre, A., Gorla, C. \& Montenegro, G., A new integrated approach for the prediction of the load independent power losses of gears: Development of a mesh-handling algorithm to reduce the CFD simulation time. Advances in Tribology, art. no. 2957151, 2016. 